\title{
Chemical quality of extracted oil and sensory quality of vacuum-fried jackfruit (Artocarpus heterophyllus Lam.) pulp as influenced by frying cycle
}

\author{
Jason D. Braga', Lorina A. Galvez ${ }^{2 *}$, Roberta D. Lauzon ${ }^{3}$ and Yan Diczbalis ${ }^{4}$
}

\begin{abstract}
Oil quality is important in the production of quality and safe fried food products. This study aimed to assess the quality of oil extracted from vacuum-fried jackfruit pulp products and the fried products at Visayas State University (VSU), Baybay City, Leyte, Philippines, with the coconut oil used until 20 frying cycles. The percent free fatty acid (FFA), acid value (AV) and peroxide value (PV) of the oil extracted from the product $\left(1^{\text {st }}, 5^{\text {th }}, 10^{\text {th }}, 15^{\text {th }} \& 20^{\text {th }}\right.$ frying cycle vacuum-fried jackfruit pulp) was determined employing titrimetric method. Quality descriptions and acceptability of the product were obtained through sensory evaluation, following standard protocols. Data were subjected to analysis of variance for significance and post hoc test to compare means. Results revealed that the increase of the frying cycle significantly $(p \leq 0.05)$ increased the peroxide value, while no significant effect was noted with free fatty acid and acid values. Aroma, taste and general acceptability of the product were significantly affected by the increase in number of frying cycle of oil due to the quality changes of the oil being used. No significant effect was observed for color and texture acceptability with frying cycle. Generally, acceptability of the product decreased with increasing frying cycle. The oil can be recycled at least 10 frying cycles to produce quality and safe vacuum-fried jackfruit product for the consuming public. The reusing of oil provides cost effectiveness in the vacuum-fried jackfruit processing.
\end{abstract}

Keywords: jackfruit, oil quality, sensory evaluation, vacuum frying

\section{INTRODUCTION}

Frying, as a complex unit operation, is essentially a cooking process that has been widely used in the food industry. Traditionally, it involves the immersion of

\footnotetext{
${ }^{1}$ Cavite State University, Philippines

${ }^{2,3}$ Department of Food Science and Technology, Visayas State University, Philippines

${ }^{4}$ Queensland Department of Agriculture Fisheries and Forestry, Australia

*Corresponding Author. Address: Department of Food Science and Technology, Visayas State University, Philippines; Email:Iorina.galvez@vsu.edu.ph
} 
foods in frying oil chambers, mostly at temperatures above the boiling point of water, bringing about a counter-flow of water bubbles and oil on the surface of the product (Dueik et al 2010). Deep-fat frying is traditionally carried out at atmospheric pressure conditions and high temperatures of up to $180^{\circ} \mathrm{C}$ (atmospheric frying). However, it had been proven that frying under atmospheric conditions leads to loss of desirable color and textural characteristic of the resulting products (Mariscal \& Bouchon 2008).

Vacuum frying is an alternative way to improve the quality of the fried food and could reduce the final oil uptake in the product (Andrés-Bello et al 2011). Vacuum frying is a deep-fat frying process, which is carried out in a closed system, below the atmospheric pressure, substantially reducing the boiling point of water and, subsequently, the frying temperature. The low frying temperatures and minimal exposure to oxygen are responsible for most of the benefits of the fried products, which include nutrient preservation (da Silva \& Moreira 2008), oil quality protection (Shyu et al 1998) and reduction in toxic compound generation (Granda et al 2004). The product is heated at low pressure; thus decreasing the boiling points of the frying oil and the water in the product. Moreover, the absence of air during vacuum frying may inhibit lipid oxidation and enzymatic browning, and therefore, the color and nutrients of samples can be largely preserved (Andrés-Bello et al 2011). Jackfruit has lots of uses. The fruit can be processed into different nutritious, delicious and acceptable products. The green fruit is used as vegetables. A number of food products have already been developed using jackfruit. This includes vacuum-fried products. This utilizes half-ripe fruits to produce bright yellow and crunchy ripe products. However, these products lack the aroma and taste of ripe jackfruit (Diamante et al 2000). In the production of vacuum-fried jackfruit pulp, maturity is critical (Lauzon 2015). The ripe fruit pulps are processed into vacuumfried and dehydrated products and both products were found highly acceptable and created a great market demand (Lauzon 2013). The VSU developed vacuum-fried jackfruit utilizes the hard ripe to ripe fruits because of its color, sweetness and aroma. The product has sweet taste, golden yellow color and a pleasant jackfruit aroma. However, vacuum-fried jackfruit from Vietnam and Thailand are processed from unripe jackfruit pulp, thus has a bland taste, though very crunchy texture (Lauzon 2014).

Jackfruit is an exotic fruit grown in tropical climates including the Indian subcontinent, southern China, southeastern Asia, middle Africa and Latin American countries. Consumers like jackfruit for its sweet, fleshy, fibrous, delicious and attractive golden yellow-colored ripe bulbs, which is the perianth portion of the fruit. It is a rich source of carbohydrates, minerals, dietary fibers and vitamins such as ascorbic acid and thiamine (Saxena et al 2009). Jackfruit contains considerably good amounts of reducing sugar, phenolics, tannin, antioxidants [specifically the EVIARC sweet variety (Galvez \& Dizon 2017)] and flavonoids which are lost due to various processing techniques including dehydration; thus makes vacuum frying technique suitable for preservation of these compounds. Frying under vacuum at lower temperatures was found to retain bioactive compounds such as total phenolics, total flavonoids and total carotenoids in jackfruit chips (Maity et al 2014).

Despite undergoing the large gain of oil during processing of the product, frying is a widely used domestic and industrial cooking technique because of its ability to generate, in the final product, a combination of texture, color and unique flavor that 
makes it a more palatable and desirable food for the consumer (Mestdagh et al 2008). Fried products are liked by all age groups and play an important role in consumers' diet because of their unique flavor and texture. However, frying involves repeated heating of oil and using it several times, most especially at the commercial scale enterprises and food companies. Exposure of cooking oil to high temperatures for long periods of time generates lipid peroxidation products that may be harmful to human health (Lapointe et al 2006).

It is in this context, that the study was conducted to evaluate the quality of oil extracted and the sensory quality of vacuum-fried jackfruit pulp as influenced by frying cycles.

\section{METHODS}

\section{Procurement of Raw Materials}

The jackfruit, specifically the EVIARC Sweet variety, used in the production of vacuum fried pulp was procured at Mahaplag, Leyte, while the frying oil (coconut oil) produced by International Pharmaceuticals Incorporated (IPI) was purchased from Ormoc City, Leyte. The chemicals used in different analyses were procured in Cebu City and all were of analytical grade.

\section{Production of Vacuum-fried Jackfruit}

The fruit was washed, brushed and rinsed with 10ppm sanitizing solution, cut into half, de-pulped and de-seeded. The pulp $(4 \mathrm{~kg})$ was blanched with enough boiling water for $1 \mathrm{~min}$ or until the pulp color changed into bright yellow and kept in a chest freezer for $24 \mathrm{~h}$. Frozen jackfruit pulps were then vacuum-fried at $89^{\circ} \mathrm{C}$ at $30 \mathrm{in}$. $\mathrm{Hg}$ vacuum for $2 \mathrm{~h}$ and $10 \mathrm{~min}$. After that, the vacuum-fried jackfruit pulps were spun to remove excess oil. Finally, the vacuum-fried pulps were sealed and packed in foil pouches. Samples for each treatment were taken for analysis. The standard procedure used by the Department of Food Science and Technology of the VSU was followed. The coconut oil was reused up to 20 frying cycles.

\section{Sample Collection and Preparation}

One hundred and fifty grams of vacuum fried jackfruit (100g for sensory evaluation \& $50 \mathrm{~g}$ for other tests) from vacuum frying cycles $1,5,10,15$ and 20 were kept in Polyethylene (PE) pouches, placed inside a close container with cover and stored in a cool, dry and clean area to maintain the quality of the products.

\section{Free Fatty Acid (FFA) Determination}

Free fatty acid value was determined using AOAC (1984) method of sample analysis with slight modification. About $15 \mathrm{~g}$ of vacuum fried jackfruit sample was placed in a $125 \mathrm{~mL}$ canonical flask, where $75 \mathrm{~mL}$ of petroleum ether was added and oil from the sample was extracted by keeping it for about $60 \mathrm{~min}$ with occasional shaking. Miscella was collected in two canonical flasks; $20 \mathrm{~mL}$ of this miscella was placed on a pre-weighed, dried petri dish and kept in a hot air oven at $80^{\circ} \mathrm{C}$ for $2 \mathrm{~h}$ for 
Chemical quality of extracted oil and sensory quality of vacuum-fried jackfruit

flask containing $20 \mathrm{~mL}$ of the miscella, $10 \mathrm{~mL}$ of neutral ethanol was added and the mix was titrated against $0.1 \mathrm{~N} \mathrm{NaOH}$, with phenolphthalein as an indicator. The FFA value was calculated using the equation:

$$
\text { FFA }(\text { as } \% \text { oleic acid })=\frac{\text { Titre value } \times \text { normality of } \mathrm{NaOH} \times 0.282 \times 100}{\text { Weight of oil in miscella }}
$$

\section{Acid Value Determination}

The acidity is expressed as free fatty acid using the formula:

$$
\text { Acid value }=\text { Percent fatty acid }(\text { as oleic acid) } \times 1.99
$$

\section{Peroxide Value Determination}

One (1) gram of oil extracted (supernatant/miscella) from the sample was taken in a canonical flask and $20 \mathrm{~mL}$ of solvent mixture ( 2 volumes of glacial acetic acid +1 volume of chloroform) was added. Thereafter, $0.5 \mathrm{~mL}$ of saturated potassium iodide solution was added to the flask with vigorous shaking and was allowed to stand for at least a minute. Then, $30 \mathrm{~mL}$ of distilled water was added and titrated against $0.1 \mathrm{~N}$ sodium thiosulphate solution, using $5 \mathrm{~mL}$ of starch solution as an indicator. The peroxide value was subsequently calculated.

$$
\text { Peroxide value }(\mathrm{meq})=\frac{\mathrm{S} \times \mathrm{N} \times 1000}{\mathrm{~W}}
$$

where:

$$
\begin{aligned}
& \mathrm{S}=\text { volume }(\mathrm{mL}) \mathrm{Na}_{2} \mathrm{~S}_{2} \mathrm{O}_{3} \text { (test-blank); } \\
& \mathrm{N}=\text { normality of } \mathrm{Na}_{2} \mathrm{~S}_{2} \mathrm{O}_{3} \text { and } \\
& \mathrm{W}=\text { mass }(\mathrm{g}) \text { of sample. }
\end{aligned}
$$

\section{Sensory Evaluation}

Sensory evaluation was carried out to determine the description and acceptability of the product from different treatments. Samples from different treatments were presented to a group of experienced panelists who evaluated the product's description on sensory parameters (color, aroma, taste, flavor \& texture) using the descriptive scoring and acceptability using 9-point Hedonic scale (Mabesa 1984).

The Incomplete Block Design (IBD) was used during the sensory evaluation. A set plan of $t=5, k=3, r=6, b=10, E=0.83$, Type $V$ was followed, where $t$ refers to the treatment, $k$ the number of samples presented to the panelist, $r$ the number of replications based on the planned IBD and $b$ the number of blocks (Cochran \& Cox 1957). A total of 50 experienced panelists evaluated three out of five treatments, where each treatment was evaluated by 30 panelists per replication. Two replications were made. 


\section{Statistical Analysis}

Data from sensory acceptability and physico-chemical analyses were analyzed statistically through one-way ANOVA with Tukey's Honestly Significant Differences for post-hoc test for differences between pairs of means and frequency for the description of sensory parameters using the commercially available software, SPSS 17 software program (SPSS Inc., Chicago, IL, USA). A p-value of less than 0.05 $(p<0.05)$ indicates statistical significance.

\section{RESULTS AND DISCUSSION}

\section{Free Fatty Acid (FFA)}

Free fatty acid content is an index of lipase activity and an indicator of freshness, storage time and stability of many fat rich foods. It is well known that free fatty acids are more susceptible to lipid oxidation, leading to reduced smoke point, rancidity and production of off-odor compared to intact fatty acids in the triglycerides. Free fatty acid has been reported to play a very important role in the aroma and flavor and also contributes to the organoleptic quality of foods when present in adequate concentration (Rosa et al 1994). Chung et al (2004) reported that water, a weak nucleophile, attacks the ester linkage of triacylglycerols and produces di- and monoacylglycerols, glycerol and free fatty acids. The percent free fatty acid of oil extracted from the product ranges from $0.1068 \pm 0.21$ to $0.1203 \pm 0.07$ showing no significant $(p \leq 0.05)$ effect (Table 1$)$. The results have increasing trend however the difference is just small that statistically non-significance was observed.

Table 1. Chemical analysis of oil extracted from vacuum fried jackfruit pulp as influenced by frying cycle

\begin{tabular}{lccc}
\hline Treatments & $\% \mathrm{FFA}^{\mathrm{ns}}$ & $\mathrm{AV}^{\mathrm{ns}}$ & $\begin{array}{c}\mathrm{PV} \\
(\mathrm{meq} \text { oxygen } / \mathrm{kg})^{*}\end{array}$ \\
\hline Cycle 1 & $0.1068 \pm 0.21$ & $0.2125 \pm 0.41$ & $4.0247 \pm 0.32^{\mathrm{d}}$ \\
Cycle 5 & $0.1127 \pm 0.17$ & $0.2243 \pm 0.33$ & $8.1876 \pm 0.34^{\mathrm{c}}$ \\
Cycle 10 & $0.1154 \pm 0.32$ & $0.2297 \pm 0.64$ & $9.6214 \pm 0.36^{\mathrm{b}}$ \\
Cycle 15 & $0.1166 \pm 0.11$ & $0.2320 \pm 0.22$ & $16.5347 \pm 0.46^{\mathrm{a}}$ \\
Cycle 20 & $0.1203 \pm 0.07$ & $0.2395 \pm 0.14$ & $17.7113 \pm 0.97^{\mathrm{a}}$ \\
\hline
\end{tabular}

Mean \pm standard deviation of replicate analysis $(n=3)$

Values with the same superscripts within the column are not significantly different $(p<0.05)$

* - significant at $p<0.05$, ns-not significant at $p \leq 0.05$

\section{Acid Value}

The acid value is also a factor that significantly affects the use of oil for industrial applications or human nutritional purposes (Akinyeyea et al 2011). It is usually twice as large as the FFA (Wilfred et al 2010). The acid value ranges from 
Chemical quality of extracted oil and sensory quality of vacuum-fried jackfruit

$0.2125 \pm 0.41$ to $0.2395 \pm 0.14 \mathrm{mg} \mathrm{NaOH}$ per $\mathrm{g}$ oil, which showed no significant $(p \leq 0.05)$ effect (Table 1). According to the Codex Alimentarius Commission (2006), the acid value for oil should be $0.6 \mathrm{mg} \mathrm{NaOH}$ per $\mathrm{kg}$ oil. All the acid value of oils extracted from the product met the standard. Acid value and FFA are related, thus if no significance, will be obtained for FFA, then same with Acid value.

\section{Peroxide Value}

Peroxide value (PV) is one of the most widely used chemical tests for the determination of the quality of fat and oil. The PV is a measure of rancidity in its early stage and shows good correlation with organoleptic flavor scores (O' Brien 1998). The unsaturated fatty acids present in the oils easily react with atmospheric oxygen and form hydroperoxides. The peroxide value of all samples ranges from $4.0247 \pm 0.32$ to $17.7113 \pm 0.97 \mathrm{meq}$ oxygen per $\mathrm{kg}$ oil. Frying cycles significantly $(p \leq 0.05)$ affect the peroxide value of oil extracted from the product. Samples from cycles 1, 5, 10 and 15 were found to be significantly $(p \leq 0.05)$ different from each other, while samples from cycle 15 and 20 were not significantly different (Table 1 ). According to Codex Alimentarius Commission (2006), the acceptable peroxide value is 10 meq oxygen per $\mathrm{kg}$ oil. Apparently, the peroxide value of the vacuum-fried jackfruit pulp from cycle 1 to 10 is still within the set standard. The peroxide value constantly increases as the number of frying cycle also increases. These variations can arise from different factors such as the degree of unsaturation of the fatty acids present in the particular oil, storage, exposure to light and the content of metals or other compounds that may catalyze the oxidation processes (Choe \& Min 2006). Muller et al (1996) found that the five unsaturated aldehydes in oxidized oils are highly cytotoxic. Based on their chemical structures, these aldehydes may show similar extents of toxicity. In fact, t-2-decenal, t, t-2,4-decadienal and t-2-undecenal have been reported to be harmful to the skin, while $t, t-2,4$-decadienal shows mucosal toxicity.

The concentration of radicals in oil used in vacuum frying possibly increases as the number of frying cycle increases, even though the raw material and/or product to be vacuum-fried has considerable amount of antioxidant in it. In this case, the raw material is jackfruit which contains useful antioxidants (Devasagayam et al 2001, Galvez \& Dizon 2017). Antioxidants are substances that neutralize free radicals or their actions (Sies 1996). Antioxidants are regarded as compounds that delay, retard, or prevent the oxidation process (Halliwell 1997). Furthermore, jackfruit also contains many carotenoids (De Faria et al 2009), including all-trans- $\beta$-carotene, which is an important antioxidant for human health (Cadenas \& Packer 1996). It is observed that the amount of peroxide in the product during the earlier stage of frying is lower but as the number of frying cycle progresses, the peroxide value correspondingly increases as the antioxidants present in the jackfruit pulp may no longer accommodate the number of free radical present in oil given that the quantity of jackfruit pulp from $1^{\text {st }}$ to $20^{\text {th }}$ frying cycle is controlled, 4 kilos each frying cycle.

\section{Sensory Evaluation}

The sensory perception of food is not a simple process because individuals are bombarded with a number of overlapping sensory attributes when food is first 
approached. Generally, the appearance aspects of the food are noticed first, since this can be perceived quickly and non-invasively. The observation step is typically followed by the ortho-nasal perception (sniff) of the odor or aroma of the food. Upon ingestion of the food, retro-nasal (in-nose) perception of the aroma continues, as well as the food's consistency and texture, taste and possibly the sound. These attributes helps to determine the quality of the food being consumed (Clark et al 2009).

\section{Color}

Food appearance is a critical feature as it is often the first attribute perceived by a consumer and serve as a primary deciding factor in so many purchasing decisions (McDougall 1983 as cited by Clark et al 2009). One of the characteristics that contribute on the appearance of food is color. The color of the food contributes immeasurably to one's aesthetic appreciation and acceptability of the product. It is used as an index to the quality of a number of foods that gives additional pleasure. The color of the vacuum-fried jackfruit pulp is yellow to golden yellow/brown (Table 2) with mean acceptability that ranges from $7.10 \pm 1.23$ to $7.55 \pm 0.93$ (Table 3 ) which is "like moderately" to "like very much" of the 9-point Hedonic Scale, implying no significant $(p \leq 0.05)$ effect. The yellow to golden yellow/brown color of the product is due to the presence of carotenoids. Carotenoids are lipid secondary metabolites that play essential roles in plants and are also relevant compounds from a nutritional standpoint (Etoh et al 2000 \& Grobush et al 2000). They attract much attention due to their proposed antioxidant properties but also as (mainly orangered) natural pigments abundant in many fruits and vegetables (like oranges, tomatoes \& carrots flowers etc.) that constitute an important part of the human diet (Edge et al 1997 \& Meléndez-Martínez et al 2014). The main carotenoids in jackfruit were shown to be all-translutein ( $24 \%$ to $44 \%$ ), all-trans- $\beta$-carotene ( $24 \%$ to $30 \%$ ), alltransneoxanthin (4\% to $19 \%)$, 9-cis-neoxanthin (4\% to $9 \%)$ and 9 -cis-violaxanthin (4\% to $10 \%$ ) (De Faria et al 2009 ).

Table 2. Description of vacuum fried jackfruit pulp as influenced by frying cycle

\begin{tabular}{ccccc}
\hline Treatment & Color & Aroma & Taste & Texture \\
\hline Cycle 1 & Yellow & Strong jackfruit & $\begin{array}{r}\text { Well-blended sweet } \\
\text { and sour }\end{array}$ & Just right crunch \\
Cycle 5 & $\begin{array}{c}\text { Golden } \\
\text { yellow/brown }\end{array}$ & Strong jackfruit & $\begin{array}{r}\text { Well-blended sweet } \\
\text { and sour }\end{array}$ & Just right crunch \\
Cycle 10 & Yellow & Strong jackfruit & Sweet & Just right crunch \\
Cycle 15 & Golden & Strong jackfruit & $\begin{array}{r}\text { Well-blended sweet } \\
\text { and sour }\end{array}$ & Just right crunch \\
Cycle 20 & $\begin{array}{c}\text { Gollow/brown } \\
\text { yellow/brown }\end{array}$ & Moderate jackfruit & $\begin{array}{r}\text { Well-blended sweet } \\
\text { and sour }\end{array}$ & Just right crunch \\
& & & & \\
\hline
\end{tabular}


Chemical quality of extracted oil and sensory quality of vacuum-fried jackfruit

Table 3. Mean acceptability of vacuum fried jackfruit pulp as influenced by frying cycle

\begin{tabular}{cccccc}
\hline Treatment & Colorns $^{\mathrm{ns}}$ & Aroma $^{*}$ & Taste $^{\star}$ & Texture $^{\mathrm{ns}}$ & $\begin{array}{c}\text { General } \\
\text { Acceptability* }\end{array}$ \\
\hline Cycle 1 & $7.55 \pm 0.93$ & $7.60 \pm 0.76^{\mathrm{a}}$ & $7.63 \pm .991^{\mathrm{ab}}$ & $7.35 \pm 1.09$ & $7.57 \pm 0.93^{\mathrm{a}}$ \\
Cycle 5 & $7.12 \pm 1.18$ & $7.45 \pm 1.16^{\mathrm{a}}$ & $7.47 \pm 1.33^{\mathrm{a}}$ & $7.62 \pm 1.01$ & $7.50 \pm 0.95^{\mathrm{a}}$ \\
Cycle 10 & $7.50 \pm 1.17$ & $6.97 \pm 1.39^{\mathrm{b}}$ & $7.48 \pm 1.17^{\mathrm{a}}$ & $7.33 \pm 1.37$ & $7.37 \pm 1.06^{\mathrm{a}}$ \\
Cycle 15 & $7.47 \pm 0.99$ & $7.28 \pm 1.06^{\mathrm{a}}$ & $7.65 \pm 0.88^{\mathrm{b}}$ & $7.68 \pm 1.05$ & $7.53 \pm 1.02^{\mathrm{a}}$ \\
Cycle 20 & $7.10 \pm 1.23$ & $6.85 \pm 1.21^{\mathrm{bc}}$ & $7.07 \pm 1.15^{\mathrm{c}}$ & $7.22 \pm 1.34$ & $7.03 \pm 1.21^{\mathrm{b}}$ \\
\hline
\end{tabular}

Mean \pm standard deviation of replicate analysis $(n=3)$

Values with the same superscripts within the column are not significantly different $(p<0.05)$

* - significant at $p<0.05, \mathrm{~ns}-$ not significant at $p \leq 0.05$

\section{Aroma}

Aroma is an attribute that emanates from our detection of the volatile compounds that are released from the food. The sense of smell is considered to be markedly more refined than the sense of taste, since an individual requires a relatively high concentration of tastant in order to perceive a taste solution (Clark et al 2009). It is another key factor in the acceptance of foods by consumers. The volatile compounds that contributed to the sweet and fruity note of jackfruit: ethyl isovalerate, 3-methylbutyl acetate, 1-butanol, propyl isovalerate, isobutyl isovalerate, 2-methylbutanol and butyl isovalerate. These compounds were consistently present in all the five jackfruit cultivars (Ong et al 2008). Fraga (2005) evaluated the odoriferous quality of the different jackfruit extracts, obtained by SDE, LLE (liquid-liquid extraction) and headspace techniques where the majority was marked by esters content (68\%), followed by alcohols (16\%), acids ( $8 \%)$ and aldehydes ( $8 \%)$. The ethylic and butyric esters (made up of C4 to C6 linear chain) dominated the global composition of jackfruit pulp. The vacuum-fried jackfruit pulp has a moderate to strong jackfruit aroma (Table 2), with mean acceptability of $6.85 \pm 1.21$ to $7.60 \pm 0.76$ (Table 3 ) which is "like moderately " to "like very much" of the 9-point Hedonic Scale, indicating statistical significance $(p \leq 0.05)$. The aroma acceptability of the vacuum-fried jackfruit pulp decreased relatively as the number of frying cycle increased which is due to the alterations of the chemical property (quality) of the oil that has been exposed to heat, moisture from the product and atmospheric oxygen (Kowalski 1991). The accumulation of FFA contributes to the sour smell (Naz et al 2005) of the vacuum-fried jackfruit, in which hydrolysis is accelerated by heat and moisture (Shimizu et al 2004). FFA has an important role in the aroma and flavor, which contributes to the organoleptic quality of foods when present in adequate concentration (Rosa et al 1994).

\section{Taste}

Taste is the sense by which the chemical qualities of food in the mouth are distinguished by the brain, based on information provided by the taste buds 
(Bradbury 2004). The vacuum fried jackfruit pulp has a sweet to well-blended sweet and sour taste with mean acceptability of $7.07 \pm 1.15$ to $7.65 \pm 0.88$ which means "like moderately" to "like very much "of the 9-point Hedonic Scale and shows statistical significance $(p \leq 0.05)$. The sweet to well-blended sweet and sour taste is associated to the maturity of the jackfruit, wherein all the jackfruit used in the study were 120 days mature. There was an increase in the number of compounds in the extracts during the ripening process. In 5 and 6 days after harvest, in ripened fruit, the compounds butyl acetate and 3-methylbutyl acetate appeared, which contributed to the fruity and floral flavor notes of the fruit (Ong et al 2006). The taste acceptability of the vacuum-fried jackfruit pulp decreased comparatively as the number of frying cycle increased which is due to the changes in the chemical property (quality) of the oil that has been exposed to heat, moisture from the product and atmospheric oxygen (Kowalski 1991) for several times. The accumulation of FFA with frying cycles contributes to the sour taste (Naz et al 2005) of the vacuum-fried jackfruit, in which hydrolysis is accelerated by heat and moisture (Shimizu et al 2004). In addition, FFA affects the aroma and flavor of the product when present in adequate concentration (Rosa et al 1994).

\section{Texture}

Texture is a complex term and is defined as the structure of the food products. Components of texture include mechanical texture (hardness, cohesiveness, adhesiveness, denseness \& chewiness), geometrical properties (smooth, grainy, chalky \& lumpy) and moisture properties (juicy, oily or greasy) (Clark et al 2009). The vacuum fried jackfruit pulp has just the right crunch texture with mean acceptability of $7.22 \pm 1.34$ to $7.68 \pm 1.05$, that is "like moderately" to "like very much" of the 9-point Hedonic scale, which indicates no significance $(p \leq 0.05)$ since the maturity and variety of jackfruit were not variable and the vacuum frying conditions were held constant throughout the study.

\section{General Acceptability}

General acceptability refers to the acceptability of the product as a whole. The vacuum-fried jackfruit pulp's mean acceptability ranged from $7.03 \pm 1.21$ to $7.57 \pm 0.93$, implying "like moderately" to "like very much" category based on the 9point hedonic scale. Results revealed that the general acceptability of the product from $1^{\text {st }}$ to $15^{\text {th }}$ frying cycle is not significantly different from each other and when each of this treatment will be compared with the $20^{\text {th }}$ frying cycle, the $20^{\text {th }}$ frying cycle was significantly $(p \leq 0.05)$ lower in terms of general acceptability rating. This is primarily because of the chemical quality (rancidity) changes in oil caused by recycling the oil several times. The general acceptability of the product was dictated by the significance of aroma and taste. Hence, the general acceptability of the product decreased with increasing number of reusing the oil in vacuum frying. This finding was validated with the findings of peroxide value analysis, where the sample from $20^{\text {th }}$ frying has the highest PV value (Table 1), indicating higher degree of rancidity which has good correlation with organoleptic flavor (O'Brien 1998). 
Chemical quality of extracted oil and sensory quality of vacuum-fried jackfruit

\section{CONCLUSIONS}

Based on the findings, the following conclusions can be drawn: peroxide value is the determining factor on the quality of oil extracted from the product; frying oil can be recycled at least 10 times; sensory acceptability is still very high even after 20 frying cycles; although the general acceptability of the product at $20^{\text {th }}$ frying cycle is still acceptable, the peroxide value is unacceptable which makes the product unsafe for consumption; and recycling of oil up to $10^{\text {th }}$ vacuum frying is more economical to the food processors.

\section{ACKNOWLEDGMENTS}

The authors would like to acknowledge the funding support from ACIAR and the ASTHRDP-NSC graduate scholarship of DOST-SEI.

\section{REFERENCES}

Akinyeyea RO, Adeyeye El, Fasakina O \& Agboolaa A. 2011. Physicochemical properties and anti-nutritional factors of palm fruit products (Elaeis Guineensis Jacq.) from Ekiti State Nigeria. Electronic Journal of Environmental, Agricultural and Food Chemistry 10(5):2190-2198

Andrés-Bello A, García-Segovia P \& Martínez-Monzó J. 2011. Vacuum Frying: An Alternative to Obtain High-Quality Dried Products. Food Engineering Reviews $3(2): 63-78$

Association of Official Analytical Chemists (AOAC). 1984. Official methods of Analysis. Association of Official Analytical Chemists (14th edn). AOAC, Arlington

Bradbury J. 2004. Taste Perception: Cracking the Code. Public Library of Science Biology 2(3):295-297

Cadenas E and Packer L. 1996. Hand book of antioxidants. Marcel Dekker, New York

Choe E and Min DB. 2006. Mechanisms and factors for edible oil oxidation. Comprehensive Reviews Food Science and Food Safety 5(4):169-186

Chung J, Lee J \& Choe E. 2004. Oxidative stability of soybean and sesame oil mixture during frying of flour dough. Journal of Food Science 69(7):574-578

Clark S, Costello M, Floyd F, Bodyfelt W \& Drake M. 2009. In Clark S, Costello M, Drake M \& Bodyfelt F (eds) Sensory Evaluation of Dairy Products (2nd edn). Springer Publisher

Cochran W and Cox G. 1957. Experimental Design (2nd edn) (pp615). John Wiley and Sons, New York

Codex Alimentarius Commission. 2006. Codex Standards for Fats and Oils from Vegetable Sources. Rome: FAO

Da Silva PF and Moreira RG. 2008. Vacuum frying of high- quality fruit and vegetable-based snacks. Lebensmittel-Wissenschaft \& Technologie-Food Science and Technology 41(10):1758-1767

De Faria AF, De Rosso VV \& Mercadante AZ. 2009. Carotenoid composition of jackfruit (Artocarpus heterophyllus) determined by HPLC-PDA-MS/MS. Plant Foods for Human Nutrition 64(2):108-115 
Devasagayam TPA, Tilak JC \& Singhal R. 2001. Functional and medicinal foods. In Losso JN, Shahidi F \& Bagchi D (eds) Functional foods in India; history and scope in angiogenesis. Marcel Dekker Inc. New York

Dueik V, Robert P \& Bouchon P. 2010. Vacuum frying reduces oil uptake and improves the quality parameters of carrot crisps. Food Chemistry 119(2010):1143-1149

Edge R, Truscoot TG \& Mcgarvey DJ. 1997. The carotenoids as antioxidants- A Review. Journal of Photochemistry and Photobiology 41(3):189-200

Etoh H, Utzunomiga Y, Komori A, Murakami Y, Oshima S \& Inakuma T. 2000. Carotenoids and human blood plasma after ingesting paprika juice. Bioscience, Biotechnology and Biochemistry 64(5):1096-1098

Fraga SRG. 2005. Investigation of volatiles and precursors of glycosylated volatiles of jackfruit (Artocarpus heterophyllus Lam.) and muruci (Byrsonima crassifolia Lam. Rich) (PhD dissertation). Federal University of Rio de Janeiro, Institute of Chemistry

Galvez LA and Dizon El. 2017. Physico-chemical and Functional Properties of Two Jackfruit (Artocarpus heterophyllus Lam.) Varieties in Eastern Visayas, Philippines. Annals of Tropical Research 39(2):100-106

Granda C, Moreira RG \& Tichy SE. 2004. Reduction of acry- lamide formation in potato chips by low-temperature vacuum frying. Journal of Food Science 69(8):405-411

Grobush K, Lanner LJ, Geleinjinse JM, Boeing H, Hofman A \& Witteman JC. 2000. Serum carotenoids and atherosclerosis. The Roterdam Study. Atherosclerosis 148(1):49-56

Kowalski B. 1991. Thermal-oxidative decomposition of edible oils and fats. DSC studies. Thermochimica Acta 184(1):49-57

Lapointe A, Couillard C \& Lemieux S. 2006. Effects of dietary factors on oxidation of low-density lipoprotein particles. Journal of Nutritional Biochemistry 17(10):645-658

Mabesa LB. 1986. Sensory evaluation of foods: Principles and Methods (pp119). College of Agriculture, University of the Philippines, Los Baños, Laguna

Maity T, Bawa AS \& Raju PS. 2014. Effect of Vacuum Frying on Changes in Quality Attributes of Jackfruit (Artocarpus heterophyllus) Bulb Slices. International Journal of Food Science 2014:1-8

Mariscal M and Bouchon P. 2008. Comparison between atmospheric and vacuum frying of apple slices. Food Chemistry 107(4):1561-1569

Meléndez-Martínez AM, Stinco CM, Brahm PM \& Vicario IM. 2014. In RodríguezConcepción M (ed) Analysis of Carotenoids and Tocopherols in Plant Matrices and Assessment of Their In Vitro Antioxidant Capacity. Plant Isoprenoids. Methods in Molecular Biology (Methods and Protocols) 2014(1153):77-97

Mestdagh F, De Wilde T, Fraselle S, Govaert Y, Ooghe W, Degroodt JM, Verhe R, Van Peteghem C \& De Meulenear B. 2008. Optimization of the blanching process to reduce acrylamide in fried potatoes. Lebensmittel-Wissenschaft \& Technologie-Food Science and Technology 41(2008):1648-1654

Muller K, Hardwick SJ, Marchant CE, Law NS, Waeg G, Esterbauer H, Carpenter KLH, \& Mitchinson MJ. 1996. Cytotoxic and chemotactic potencies of several aldehydic components of oxidised low density lipoprotein for human monocytemacrophages. Federation of European Biochemical Societies Letters 388(23):165-168 
Chemical quality of extracted oil and sensory quality of vacuum-fried jackfruit

Naz S, Siddiqi R, Sheikh H \& Sayeed SA. 2005. Deterioration of olive, corn and soybean oils due to air, light, heat and deep-frying. Food Research International 38(2):127-134

O' Brien RD. 1998. Fats and Oils: Formulating and Processing for Applications. Technomic Publishing Company, Inc, Pennsylvania

Ong BT, Tan CP, Hamid N \& Rusul G. 2008. Analysis of volatile compounds in five jackfruit (Artocarpus heterophyllus L.) cultivars using solid-phase microextraction (SPME) and gas chromatography-time-of-flight mass spectrometry (GC-TOFMS). Journal of Food Composition and Analysis 21(5): 416-422

Ong BT, Nazimah SAH, Osman A, Quek SY, Voon YY \& Hashim DM. 2006. Chemical and flavor changes in jackfruit (Artocarpus heterophyllus Lam.) cultivar J3 during ripening. Postharvest Biology and Technology 40(3):279-286

Rosa P, Alicia S \& Angel M. 1994. Determination of Free Fatty Acid in Foods by Flow Injection. Journal of Science Food and Agriculture 66(4):473-479

Saxena A, Bawa AS \& Raju PS. 2009. Phytochemical changes in fresh-cut jackfruit (Artocarpus heterophyllus L.) bulbs during modified atmosphere storage. Food Chemistry 115(4):1443-1449

Shyu S-L, Hau LB \& Hwang LS. 1998. Effect of vacuum frying on the oxidative stability of oils. Journal of the American Oil Chemists' Society 75(10):13931398

Sies H. 1996. Antioxidants in disease, mechanisms and therapy (1st edn). New York: Academic Press

Wilfred S, Adubofuor J \& Oldham JH . 2010. Optimum conditions for expression of oil from Allanblackia floribunda seeds and assessing the quality and stability of pressed and solvent extracted oil. African Journal of Food Science 4(9):563570 